\title{
ANTICORPOS POLICLONAIS PARA O IMUNODIAGNÓSTICO DE VÍRUS BOVINO
}

\section{POLYCLONAL ANTIBODIES FOR THE IMMUNODIAGNOSTIC OF BOVINE VIRUSES}

\author{
Tatiane Goulart de Lima1 ORCID - http://orcid.org/0000-0002-5525-3297 \\ Luana Marchi Quadros ${ }^{1}$ ORCID - http://orcid.org/0000-0001-6746-2291 \\ Leandro Abel Mallmann1 ORCID - http://orcid.org/0000-0002-4196-9905 \\ Mário Celso Sperotto Brum ${ }^{1 *}$ ORCID - http://orcid.org/0000-0002-1643-1126 \\ ${ }^{1}$ Universidade Federal do Pampa, Uruguaiana, RS, Brasil. \\ *Autor para correspondência - mariobrum@unipampa.edu.br
}

\section{Resumo}

O objetivo do estudo foi produzir anticorpos policlonais para vírus bovino e testar a reatividade em imunoensaios como imunofluorescência, imunoperoxidase e slot blot. Como imunógeno utilizouse cepas e/ou isolados dos herpesvírus bovino tipo 1, 2 e 5 (BoHV-1, BoHV-2 e BoHV-5), vírus da diarreia viral bovina (BVDV), vírus respiratório sincicial bovino (BRSV), vírus da língua azul (BTV) e vírus vaccina (VACV) amplificados em cultivo celular. Os coelhos foram imunizados em intervalos regulares e o soro hiperimune produzido foi utilizado como anticorpo primário nos imunoensaios. A diluição de trabalho para cada antissoro foi determinada por diluição seriada limitante e variaram entre 1:800 e 1:51.200. As maiores diluições foram observadas para imunoperoxidase, quando comparadas com a imunofluorescência e slot blot. Diluições menores que 1:800 foram associadas com aumento de reações inespecíficas. Os antissoros anti-BoHV-1, -BoHV-5, -BVDV e -BRSV reagiram frente a isolados heterólogos em ensaios de imunofluorescência e imunoperoxidase. Conclui-se que os antissoros produzidos possuem elevadas concentrações de anticorpos específicos para os vírus e é uma alternativa para a utilização em imunoensaios.

Palavras-chave: antissoro, detecção viral, imunoensaio, diagnóstico.

\begin{abstract}
The objective of the study was to produce polyclonal antibodies to bovine viruses and to test the reactivity in immunoassays such as immunofluorescence, immunoperoxidase and slot blot. Bovine viral diarrhea virus (BVDV), bovine respiratory syncytial virus (BRSV), bovine herpesvirus type 1, 2 and 5 (BoHV-1, BoHV-2 and BoHV-5) blue tongue virus (BTV) and vaccinia virus (VACV) were amplified in cell culture and used to immunize rabbits. Animals were immunized at regular intervals and the hyper immune serum produced was used as primary antibody in the immunoassays. The working dilution for each antiserum was determined by limiting serial dilution and varied from 1: 800 to 1: 51,200. The highest dilutions were observed for immunoperoxidase, when compared with immunofluorescence and slot blot. Dilutions lower than 1:800 were associated with the presence of nonspecific reactions. Anti-BoHV-1, -BoHV-5, -BVDV and -BRSV antisera reacted against heterologous isolates in immunofluorescence and immunoperoxidase assays. It is concluded that the produced polyclonal antibodies have high concentrations of virus-specific antibodies and are an alternative for use in immunoassays.
\end{abstract}


Keywords: antiserum, viral detection, immunoassay, diagnostic.

Recebido em 28 de abril de 2017.

Aceito em 17 de abril de 2019.

\section{Introdução}

Os vírus possuem características morfológicas e estratégias de replicação bastante variáveis. Assim sendo, inúmeras metodologias para identificação e caracterização da estrutura viral e do ciclo replicativo foram desenvolvidas ${ }^{(1)}$. Estes ensaios baseiam-se na: detecção dos vírions; observação de propriedades biológicas; detecção de antígenos ou genoma viral e detecção da resposta imune específica $^{(1)}$. Essas técnicas possuem variações quanto à metodologia, sensibilidade, especificidade e custo de execução ${ }^{(2)}$. Os imunoensaios para detecção de antígenos virais foram desenvolvidos nos anos de 1960 e, desde então, são amplamente utilizados na rotina de pesquisa e diagnóstico viral. A difusão desses ensaios deve-se a facilidade de execução, repetibilidade, disponibilidade de reagentes e resultados produzidos ${ }^{(3)}$.

Os imunoensaios baseiam-se na reação específica vírus-anticorpo, seguido da revelação por enzimas ou fluorocromos ${ }^{(4)}$. Diversos ensaios que empregam este princípio estão disponíveis, entre os quais se destacam imunofluorescência (IFA), imunoperoxidase (IPX), imuno-histoquímica (IHQ), Western blot e enzyme-linked immunosorbent assay (ELISA). Esses testes são aplicados na detecção de antígenos em células de cultivo, tecidos de animais ou livres no meio ${ }^{(3)}$. Desse modo, essas metodologias estão condicionadas à disponibilidade de anticorpos específicos para o vírus ou antígeno viral ${ }^{(2)}$. Os reagentes são obtidos comercialmente ou então produzidos de acordo com a necessidade do laboratório(4).

Os anticorpos utilizados nos imunoensaios podem ser monoclonais ou policlonais, de acordo com a metodologia e características de produção ${ }^{(4)}$. Vários anticorpos monoclonais ou policlonais para diagnóstico de viroses bovinas estão disponíveis comercialmente, ou então, são produzidos pelos próprios laboratórios. Em diversas situações, a obtenção desses reagentes depende de importação, que além de ser demorada, eleva consideravelmente os custos.

O rebanho bovino brasileiro é composto por mais de 200 milhões de animais e está susceptível a diversos agentes virais, entre os quais se destacam o herpesvírus bovino tipos 1 e 5 (BoHV 1 e 5), vírus da diarreia viral bovina (BVDV), vírus respiratório sincicial bovino (BRSV), vírus da língua azul (BTV) e vírus da vaccínia (VACV), entre outros ${ }^{(5,6,7,8,10)}$. O diagnóstico laboratorial dessas enfermidades pode ser realizado pela detecção das partículas ou material genético viral. Diversas técnicas como imunofluorescência, imunoperoxidade e ELISA são empregadas como alternativas para a identificação e diagnóstico de partículas víricas ${ }^{(1,3)}$. Esses testes são rotineiramente utilizados em laboratórios de diagnóstico e pesquisa para identificar a presença de antígenos virais em amostras suspeitas ${ }^{(1,3)}$. Um limitante para a utilização dos imunoensaios para os laboratórios é a disponibilidade dos anticorpos ou antissoros ${ }^{(3)}$. O objetivo deste trabalho foi produzir anticorpos policlonais para vírus bovinos e avaliar a sua reatividade em ensaios de imunofluorescência, imunoperoxidase e slot blot.

\section{Material e métodos}

Os procedimentos de multiplicação e quantificação viral foram realizados em células de linhagem (Tabela 1). As células foram mantidas em meio essencial mínimo (MEM) ou meio RPMI de acordo com as características de cultivo, ambos os meios contendo penicilina $(1,6 \mathrm{mg} / \mathrm{L})$ e estreptomicina $(0,4$ 
$\mathrm{mg} / \mathrm{L}$ ), suplementado com $5 \%$ de soro fetal bovino ou soro equino ${ }^{(5,6)}$. Para produção dos anticorpos policlonais utilizou-se cepas e/ou isolados de vírus bovinos (Tabela 1). Ainda, a reatividade cruzada de alguns antissoros foi testada contra diferentes isolados heterólogos, esses foram anti-BoHV 1 (SV 169/06, SV 453/93, SV 299/03), anti-BoHV 5 (SV 71/07D, SV 437/07, SV 511/09, 97/642, SV 344/06), anti-BVDV (NADL, SV 66/07, SV 260, SV 56/03, SV 713/09, SV 241/10) e anti-BRSV (SP 24/05/99), respectivamente. As células e amostras virais foram gentilmente cedidas pelo Setor de Virologia da Universidade Federal de Santa Maria (UFSM).

Tabela 1. Imunógenos utilizados e diluições de trabalho dos antissoros obtidos frente aos vírus homólogos em imunoensaios

\begin{tabular}{|c|c|c|c|c|c|c|c|}
\hline \multirow{2}{*}{ Imunógeno } & \multirow{2}{*}{ Identificação } & \multirow{2}{*}{ Célula } & \multirow{2}{*}{$\begin{array}{l}\text { Titulo } \\
\text { viral }^{\mathbf{a}}\end{array}$} & \multirow{2}{*}{ Animal } & \multicolumn{3}{|c|}{ Diluição de trabalho } \\
\hline & & & & & IFI $^{\mathbf{b}}$ & IPMA $^{c}$ & Slot-blot \\
\hline \multirow{2}{*}{ BoHV 1} & \multirow{2}{*}{ Cooper } & \multirow{2}{*}{ CRIB } & \multirow{2}{*}{$10^{7,3}$} & 2.1 & $1: 1.600$ & $1: 12.800$ & $1: 8.000$ \\
\hline & & & & 2.2 & $1: 12.800$ & $1: 51.200$ & $\mathrm{NT}^{\mathrm{d}}$ \\
\hline BoHV 5 & SV 507 wt & CRIB & $10^{6,5}$ & 7.1 & $1: 1.600$ & $1: 800$ & $1: 2.000$ \\
\hline \multirow{2}{*}{ BoHV 5 gE $\Delta$} & \multirow{2}{*}{ SV 507gE $\Delta$} & \multirow{2}{*}{ CRIB } & \multirow{2}{*}{$10^{6,8}$} & 18.1 & $1: 1.600$ & $1: 3.200$ & NT \\
\hline & & & & 18.2 & $1: 1.600$ & $1: 800$ & NT \\
\hline \multirow{2}{*}{ BoHV 2} & \multirow{2}{*}{ Nebraska } & \multirow{2}{*}{ CRIB } & \multirow{2}{*}{$10^{5,1}$} & 21.1 & $1: 1.600$ & $1: 25.600$ & $1: 10.000$ \\
\hline & & & & 21.2 & $1: 1.600$ & $1: 25.600$ & NT \\
\hline \multirow{2}{*}{ BVDV } & \multirow{2}{*}{ Singer } & \multirow{2}{*}{ MDBK } & \multirow{2}{*}{$10^{6,8}$} & 4.1 & $1: 1.600$ & $1: 12.800$ & $1: 10.000$ \\
\hline & & & & 4.2 & $1: 1.600$ & $1: 12.800$ & NT \\
\hline BRSV & BRSV & MDBK & $10^{5,3}$ & 5.1 & $1: 1.600$ & $1: 6.400$ & $1: 6.000$ \\
\hline BTV & Sorotipo 4 & BHK-21 & $10^{5,1}$ & 16.1 & $1: 1.600$ & $1: 12.800$ & $1: 10.000$ \\
\hline \multirow{2}{*}{ VACV } & \multirow{2}{*}{ VACV P1V } & \multirow{2}{*}{ VERO } & \multirow{2}{*}{$10^{4,8}$} & 24.1 & $1: 6.400$ & $1: 25.600$ & $1: 20.000$ \\
\hline & & & & 24.2 & $1: 6.400$ & $1: 12.800$ & NT \\
\hline
\end{tabular}

Para a produção do imunógeno foi utilizado o sobrenadante de cultivos celulares infectados. Para isso, monocamadas de células foram previamente preparadas em frascos T-75 $\left(75 \mathrm{~cm}^{2}\right)$, inoculados com uma amostra dos vírus descritos na Tabela 1. O sobrenadante foi coletado quando o efeito citopático (ECP) atingiu aproximadamente $90 \%$ das células. Este foi então centrifugado a $1.500 \mathrm{xg} / 10 \mathrm{~min}$. a $4{ }^{\circ} \mathrm{C}$, aliquotado e congelado a $-70{ }^{\circ} \mathrm{C}$ até o momento do uso. A amostra viral do vaccínia, com potencial zoonótico e patogênico para coelhos, foi inativada. A inativação do sobrenadante do cultivo foi realizada a $56{ }^{\circ} \mathrm{C}$ durante $2 \mathrm{~h}$ e posteriormente misturado com adjuvante hidróxido de alumínio a 20\% (Hipra Saúde Animal LTDA).

Coelhos com aproximadamente 60 dias de idade foram utilizados para a produção de anticorpos. A utilização, manutenção e manipulação dos animais seguiram as normas de bem-estar animal e foram previamente aprovadas pela Comissão de Ética no Uso de Animais (CEUA), da Universidade Federal do Pampa (registro $n^{\circ}$ 005/2011) e recomendadas pelo Colégio Brasileiro de Experimentação Animal (COBEA). Os animais foram imunizados cinco vezes com intervalos aproximados de 14-21 dias (0, 21, 35, 49 e 65 dias pós-vacinação - dpv). O volume administrado foi de $1 \mathrm{~mL}$ via subcutânea para sobrenadante contendo vírus vivo, ou então, pela via intramuscular com o imunógeno inativado. No dia $70 \mathrm{dpv}$, com os animais sob anestesia geral profunda (Zoletil 50®, Virbac), realizou-se a coleta de sangue total por punção cardíaca e os animais foram posteriormente eutanasiados. O soro obtido após a separação do coágulo foi aliquotado, identificado e armazenado a $-20^{\circ} \mathrm{C}$ até o momento dos testes.

A reatividade dos soros hiperimunes foi avaliada em ensaios de imunofluorescência, imunoperoxidase e slot blot. Todos esses ensaios foram realizados em duplicata e repetidos em duas ocasiões distintas. Anterior aos testes, os anticorpos policlonais foram diluídos em PBS estéril, pH 7,2 (1:100 até 1:204.800). Cada diluição foi testada frente ao vírus homólogo como controle positivo, e células 
não infectadas como controle negativo. A determinação da diluição de trabalho, para cada um dos imunoensaios, foi considerada a maior diluição que apresentou reação positiva específica nas células infectadas, e ausência de reação nas células não infectadas.

Os antissoros foram testados pela técnica de IFI conforme descrito por BOTTON et al. ${ }^{(5)}$. Para tanto, células infectadas e não infectadas foram preparadas e adsorvidas em lâminas multispots e incubadas em câmara úmida por $2 \mathrm{~h}$ a $37{ }^{\circ} \mathrm{C}$ com atmosfera de $5 \% \mathrm{CO}_{2}$. Para a infecção das células, utilizou-se multiplicidade de infecção de 0,1 (MOI 0.1). A fixação das células foi realizada com acetona absoluta por três minutos a $4^{\circ} \mathrm{C}$, lavadas em água destilada, e secas em temperatura ambiente. As diferentes diluições dos antissoros foram testadas como anticorpo primário, incubadas em câmara úmida por 1h a $37^{\circ} \mathrm{C}$ e lavadas três vezes em PBS e água destilada. Como anticorpo secundário, utilizou-se anticorpo de cabra anti-IgG de coelho conjugado com isotiocianato de fluoresceína (FITC), com incubação em câmara úmida por $1 \mathrm{~h} \mathrm{a} 37^{\circ} \mathrm{C}$ e lavagens, conforme descrito anteriormente. Posteriormente, as células foram coradas com Azul de Evans, montadas com glicerol:PBS (50:50) e lamínulas e observadas ao microscópio de epifluorescência. A reatividade foi revelada pela visualização de células coradas em verde fluorescente.

A IPMA foi realizada em placas de 96 cavidades contendo células infectadas e não infectadas seguindo o protocolo descrito por BOTTON et al. ${ }^{(5)}$. As cavidades contendo vírus foram infectadas com 25 TCID50/poço. As monocamadas foram fixadas com acetona:metanol (50:50) por $10 \mathrm{~min}$. em temperatura ambiente e, posteriormente, lavadas três vezes com PBS pH 7,2. As reações inespecíficas foram bloqueadas com 5\% de leite em pó desnatado diluído em PBS + 0,05\% Tween 20 (PBST) por 30 min. a $37^{\circ} \mathrm{C}$, seguidas de dois ciclos de lavagens com PBST. As diluições do anticorpo primário foram incubadas pelo período de $1 \mathrm{~h}$ a $37^{\circ} \mathrm{C}$ sob agitação constante, seguido de três lavagens com PBST. O anticorpo secundário, anticorpo de cabra anti-IgG de coelho conjugado com peroxidase (HRPO) foi adicionado e incubado por $1 \mathrm{~h}$ a $37^{\circ} \mathrm{C}$ sob constante agitação, sucedido de lavagens conforme descrito anteriormente. As reações foram reveladas pela adição do substrato de AEC [solução 0,05 M tampão acetato de sódio ( $\mathrm{pH} 5,2$ ), contendo 5,2\% de 3-amino-9-etilcarbazole (AEC) e 0,8\% de peróxido de hidrogênio]. A revelação foi interrompida com a adição de PBS após 20 min. da adição do substrato. A avaliação foi realizada com auxílio de microscópio óptico invertido, e as reações positivas foram confirmadas pela coloração carmim nas células infectadas.

A capacidade do antissoro em reconhecer proteínas imobilizadas em membranas de nitrocelulose foi realizada pela técnica de slot blot. Lisados de células infectadas (MOI 5) e não infectadas foram preparados com tampão de lise NP-40 ${ }^{(4)}(150 \mathrm{mM} \mathrm{NaCl}+0,1 \%$ Triton X-100 + $50 \mathrm{mM}$ Tris $\mathrm{HCl} \mathrm{pH}$ 8,0). Para o BTV e VACV foram utilizados sobrenadantes de cultivos infectados e não infectados como antígenos. Os lisados ou sobrenadantes foram transferidos para membranas de nitrocelulose com o auxílio de vácuo e de um aparelho de slot blot (Gibco Life Technologies). Posteriormente, as membranas foram bloqueadas com PBST $+5 \%$ leite em pó desnatado por $1 \mathrm{~h}$, em temperatura ambiente, seguido de três lavagens com PBS. Como anticorpo primário foi utilizado diferentes diluições dos antissoros. As incubações do anticorpo primário e secundário foram realizadas conforme descrito para o ensaio de IPMA. A reação positiva foi revelada pela adição do substrato AEC e posterior observação de marcação das "bandas" na coloração carmim.

\section{Resultados}

As imunizações dos animais produziram antissoros capazes de reagir especificamente com antígenos virais em três diferentes imunoensaios (Tabela 1). Geralmente, as diluições de trabalho 
para imunofluorescência foram inferiores às diluições de trabalho para a imunoperoxidase e slot blot (Tabela 1). Ainda, diluições inferiores a 1:800 produziram reações inespecíficas com células não infectadas. Durante os procedimentos de imunização, não foram observadas reações locais ou sistêmicas nos animais. Um animal (\#7.2) imunizado com o vírus BoHV 5 (SV 507 wt) morreu no dia 50 dpv de causas não relacionadas com a imunização.

No teste de imunofluorescência, foi detectada marcação verde fluorescente nas membranas citoplasmáticas e/ou difusas no citoplasma das células infectadas, dependo da espécie viral (Figura 1). As diluições de trabalho variaram de 1:1.600 para a maioria dos antissoros, até 1:12.800 para o antissoro do BoHV 1 (Tabela 1). As reações inespecíficas foram observadas com maior intensidade quando se utilizou os soros anti-BTV e anti-VACV, porém com possibilidade de diferenciação entre células infectadas e não infectadas. O teste de IFI utilizando o antissoro anti-BVDV não produziu reação clara e específica com células infectadas e fixadas com acetona. Assim sendo, utilizou-se paraformaldeído (5,5\%) para fixar e Triton X-100 (0,05\%) para permeabilizar as células. Após esse tratamento, observou-se marcação positiva nas células infectadas e diminuição considerável das reações inespecíficas.

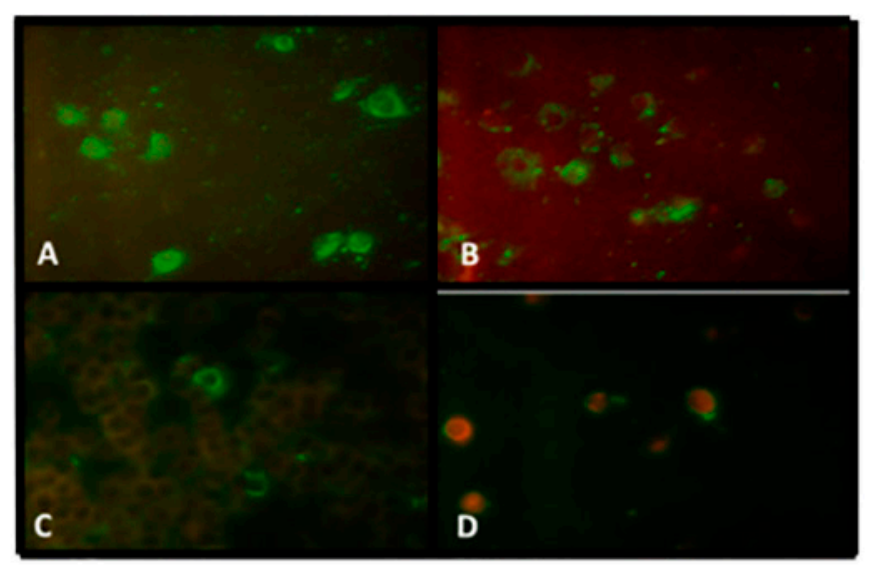

A - herpesvirus bovino 2 (BoHV 2); B - herpesvirus bovino 5 (BoHV 5); C - vírus respiratório e sincicial bovino (BRSV) e D - virus da lingua azul (BTV). Aumento 400x.

Figura 1. Detecção de células infectadas com diferentes vírus bovinos pela técnica de imunofluorescência. Anticorpos policlonais produzidos em coelhos utilizados como anticorpos primários.

$\mathrm{Na}$ IPMA, os antissoros reagiram especificamente com as células infectadas com os vírus homólogos e produziram coloração carmim difusa no citoplasma destas (Figura 2). Essa coloração não foi observada nas células controle não infectada. Houve grandes variações nas diluições de trabalho estabelecidas para este ensaio (1:800 a 1:51.200) (Tabela 1). Novamente, os antissoros anti-BTV e anti-VACV reagiram inespecificamente de forma mais intensa. Assim como na IFI, a IPMA dos antissoros antiBVDV frente às células infectadas com BVDV e fixadas com acetona:metanol (50:50) produziram reações fracas ou nulas, indistinguíveis dos controles negativos. No entanto, a fixação das células com paraformaldeído $(5,5 \%)$ e permeabilização com Triton X-100 produziu reações específicas, que puderam ser diferenciadas entre células infectadas e não infectadas. A capacidade dos antissoros anti: BoHV 1, BoHV 5, BVDV e BRSV de reagirem frente a amostras heterólogas foi realizada por IFI e IPMA, nas quais testou-se somente a diluição de trabalho de cada antissoro estabelecida previamente. Todos os antissoros testados foram capazes de reconhecer amostras heterólogas dos vírus, demonstrando ampla reatividade. 


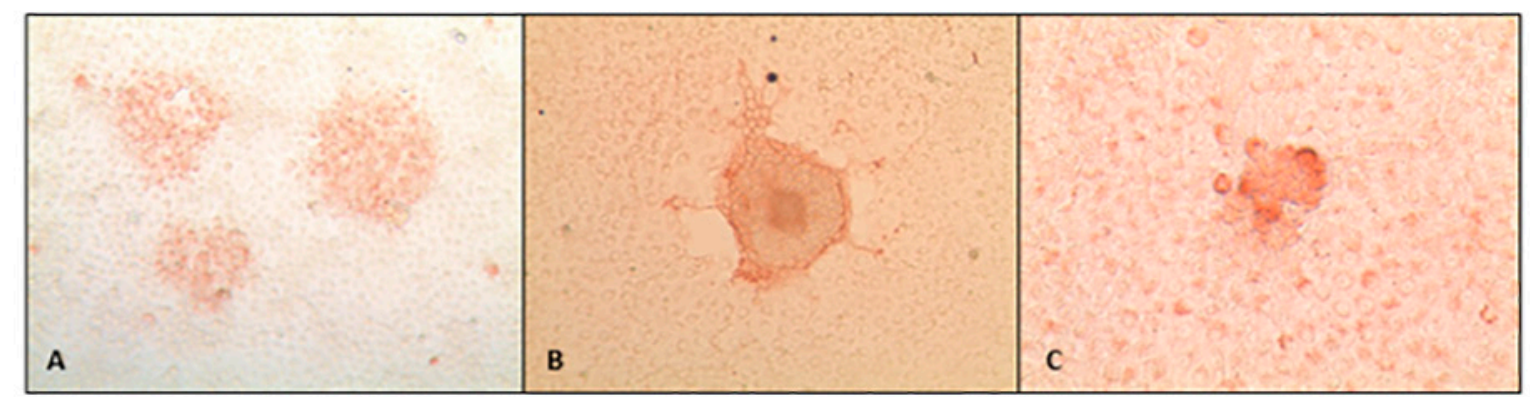

A - herpesvirus bovino 1 ( $\mathrm{BoHV}$ 1); $\mathrm{B}$ - herpesvirus bovino 2 ( $\mathrm{BoHV} 2$ ) e $\mathrm{C}$ - virus respiratório e sincicial bovino. Aumento $400 \mathrm{x}$.

Figura 2. Cultivos celulares de MDBK infectadas individualmente com diferentes vírus bovinos e submetidas à técnica imunoperoxidase utilizando anticorpos policlonais.

Os antissoros reagiram especificamente na técnica de slot blot e foi possível a visualização da marcação específica de cor carmim nos lisados de células infectadas. As diluições de trabalho dos antissoros estabelecidas para essa técnica estão apresentadas na Tabela 1. Assim como na IFI e IPMA, diluições menores antissoro produziram reações inespecíficas e inibição destas foi obtida após a diluição dos anticorpos primários.

De um modo geral, os resultados demonstraram que os antissoros produzidos em coelhos, após cinco imunizações, foram capazes de reconhecer de forma específica antígenos virais em três diferentes técnicas. Esses antissoros foram capazes de detectar os antígenos homólogos e, em alguns casos, antígenos heterólogos em diferentes imunoensaios podendo ser utilizados na detecção destes agentes.

\section{Discussão}

Anticorpos policlonais específicos para oito importantes viroses de bovinos foram produzidos e a reatividade destes avaliada em imunoensaios. Para tanto, coelhos foram imunizados com sobrenadante de cultivos celulares infectados com cepas ou isolados de BoHV 1, BoHV 5, BoHV 5 gE $\Delta$, BoHV 2, BVDV, BRSV, BTV e VACV. A reatividade dos anticorpos policlonais foi demonstrada em testes de imunofluorescência, imunoperoxidase e slot blot. Com os resultados obtidos foi possível produzir antissoros que podem ser usados em testes laboratoriais de viroses que acometem o rebanho brasileiro. No entanto, a caracterização completa dos antissoros depende de testes complementares e adicionais para avaliar parâmetros como especificidade, linearidade, precisão e sensibilidade.

Os vírus selecionados para produção dos antissoros são responsáveis por infecções em bovinos no Brasil e no mundo ${ }^{(5,7,8,9)}$. Diversos surtos dessas enfermidades foram diagnosticados e caracterizados por meio de técnicas laboratoriais, como os imunoensaios ${ }^{(5,7,10)}$. No entanto, em algumas situações, a demonstração da presença viral foi realizada somente por métodos moleculares, muito provavelmente pela indisponibilidade de anticorpos ${ }^{(8)}$, demonstrando assim a necessidade da disponibilização destes reagentes.

O volume de soro hiperimune produzido é definitivo e acredita-se que seja suficiente para a realização de inúmeros ensaios, pois as diluições de trabalho foram de moderadas e elevadas (Tabela 1). Dentre os aspectos positivos da produção dos anticorpos policlonais estão o custo de obtenção e tempo de produção ${ }^{(4)}$. Esses anticorpos foram consideravelmente inferiores quando comparado 
com a aquisição comercial, sendo que muitas vezes necessitam ser importados e estão sujeitos aos trâmites alfandegários. O tempo e custo de produção de anticorpos monoclonais também são bastante superiores ao necessário para a produção dos antissoros ${ }^{(4)}$. As principais desvantagens dos antissoros são: heterogeneidade das imunoglobulinas específicas para diferentes epítopos do mesmo antígeno; presença de outros anticorpos do hospedeiro, capacidade de produção limitada; falta de homogeneidade entre os animais e diferenças nas coletas de um mesmo animal ${ }^{(4)}$. Esses fatores contribuem para a formação de reações inespecíficas. A alternativa para redução das reações indesejáveis é a purificação dos anticorpos específicos com o uso de colunas de afinidade ${ }^{(4)}$. Esse procedimento é recomendado para testes laboratoriais que exigem certificações.

Os imunoensaios são utilizados para identificar e caracterizar a presença viral em amostras clínicas e de pesquisa $^{(3)}$. No entanto, a execução destes ensaios requer anticorpos que reajam especificamente com antígenos virais ${ }^{(3)}$. A seleção do tipo de anticorpo a ser utilizado varia de acordo com disponibilidade do antígeno, especificidade, aplicação, volume de anticorpo desejado e infraestrutura disponível para produção ${ }^{(4)}$. Pela facilidade de manipulação, custo e volume de soro, optou-se por coelhos para produção do soro hiperimune.

Os anticorpos policlonais são amplamente usados para diagnóstico e caracterização de amostras virais $^{(5)}$. A ampla diversidade de anticorpos presentes nos antissoros é uma vantagem que contrasta com a especificidade única dos anticorpos monoclonais. Essa característica é desejável para a detecção de epítopos conversados ou então para avaliar a variabilidade em testes de caracterização antigênica de diversos isolados ${ }^{(5,10)}$. Esta ampla reatividade é comum nos soros policlonais, pois estes possuem anticorpos capazes de reagir frente a antígenos conservados e variáveis de proteínas estruturais e não estruturais dos vírus ${ }^{(5,11)}$.

Nos ensaios de IFI, IPMA e slot blot realizados não foi possível determinar a especificidade dos anticorpos presentes nos antissoros. No entanto, pelo fato do imunógeno utilizado ser constituído de sobrenadante de cultivo celular, acredita-se que os antissoros apresentem anticorpos contra diversas proteínas virais. A confirmação inequívoca da reatividade específica dos antissoros seria possível com a realização de testes de Western-blot ou imunoprecipitação. Ainda, a utilização desse tipo de reagente tem aplicação em ensaios de sorologia cruzada para demonstrar a diversidade antigênica, como nos casos de BoHV 1, BoHV 5 e BVDV ${ }^{(5,11)}$. Além da aplicabilidade nos ensaios de IFI, IPMA e slot-blot, não pode ser descartado o emprego desses reagentes em testes de neutralização, ELISA, Western-blot, entre outros.

Uma característica marcante entre os isolados de campo do BVDV é a diversidade antigênica. Esse fator pode dificultar ou até mesmo produzir resultados falsos negativos no momento da identificação de possíveis amostras virais ${ }^{(5)}$. Devido ao fato da capacidade de reconhecimento de inúmeros epítopos, os anticorpos policlonais são considerados uma boa alternativa para minimizar a questão da variabilidade antigênica, uma vez que os anticorpos policlonais possuem maior capacidade de reconhecer variantes do $\mathrm{BVDV}^{(5)}$. Ainda, a utilização de uma mistura de duas ou mais amostras virais para a produção de um antissoro certamente aumentaria a capacidade reativa dos anticorpos.

Nos testes de imunofluorescência e imunoperoxidase, os antígenos estavam presentes no interior das células infectadas e diferentes padrões de coloração foram detectados, especialmente no caso de imunofluorescência. As células infectadas com os herpesvírus, BRSV e VACV, apresentaram coloração verde difusa no citoplasma e nas células infectadas com BTV observaram-se regiões localizadas com coloração e outras áreas com ausência de marcação. A fixação das células com acetona ou acetona:metanol impediu a ocorrência de reação positiva para BVDV. A alteração do agente fixador, tanto para IFI como para IPMA, possibilitou a identificação de reações específicas. Esse 
mesmo efeito foi relatado utilizando monoclonais para o BVDV(11). A acetona pode ter alterado os epitopos conformacionais, impossibilitado a ligação dos anticorpos. Devido à reatividade inespecífica observada na IFI e IPMA, a fonte de antígeno para o slot blot do BTV e VACV foi o sobrenadante de cultivos infectados. Com essa alteração as reações inespecíficas foram eliminadas. Deste modo, podese sugerir que uma das causas das reações inespecíficas na IFI e IPMA desses antissoros foi devido a proteínas celulares contaminantes do antígeno viral utilizado para imunizar os animais.

A reatividade dos antissoros nos testes de imunofluorescência, imunoperoxidase e slot blot demonstraram que reações inespecíficas ocorrem em diluições baixas, mesmo nos controles de células não infectadas. Esse tipo de reação é comum de ocorrer com anticorpos policlonais ${ }^{(4)}$. Os antissoros anti-BTV e anti-VACV apresentaram as reações inespecíficas mais intensas. A origem destas reações pode ser atribuída à presença de antígenos celulares contaminando o imunógeno. A resolução deste problema foi a diluição do antissoro. No entanto, para evitar estas reações indesejáveis é recomendável a purificação do imunógeno, a adsorção dos antissoros com lisados celulares, ou então, a purificação dos anticorpos com colunas de afinidades ${ }^{(4)}$.

\section{Conclusão}

Os resultados demonstram a produção de anticorpos policlonais de forma rápida e capaz de reconhecer antígenos virais em testes de imunofluorescência, imunoperoxidase e slot-blot. A utilização desses ensaios pode auxiliar na implantação de técnicas de diagnóstico ou investigação científica em laboratórios de virologia. Assim sendo, é possível obter reagentes para a utilização no diagnóstico e investigação da circulação de importantes viroses presentes no rebanho bovino brasileiro. A futura purificação dos anticorpos específicos, bem como a determinação da sensibilidade, especificidade e capacidade neutralizante aumentarão a sua aplicabilidade.

\section{Agradecimentos}

À Fundação de Amparo à Pesquisa do Estado do Rio Grande do Sul (FAPREGS) pelo apoio financeiro (ARD 10/0222-0).

\section{COMITÊ DE ÉTICA E BIOSSEGURANÇA}

Registro $n^{\circ}$ 005/2011 - Comissão de Ética no Uso de Animais (CEUA)/ Universidade Federal do Pampa.

\section{Referências}

1. Lima TG. Produção e avaliação de anticorpos policlonais para vírus bovino. Dissertação de Mestrado. Programa de Pós-Graduação em Ciência Animal, Universidade Federal do Pampa. 2013. 51p. Available form: http://dspace.unipampa.edu.br/bitstream/riu/179/1/117110029.pdf

2. Maclachlan N, Dubovi EJ. Fenner's veterinary virology. 4nd ed. London: Academic Press; 2011. 534p. English.

3. Kennedy M. Methodology in diagnostic virology. Vet Clin North Am Exot Anim Pract. 2005; 8(1):7-26. 
4. Harlow E, Lane D. Antibodies: a laboratory manual. 1nd ed. Cold Spring Harbor Laboratory, Cold Spring Harbor, New York; 1988.. 726p. English.

5. Botton SA, Silva AM, Brum MCS, Weiblen R, Flores EF. Antigenic characterization of Brazilian bovine viral diarrhea virus isolates by monoclonal antibodies and cross-neutralization. Braz J Med Biol Res. 1998; 31(11): 1429-1438.

6. Cargnelutti JF, Schmidt C, Masuda EK, Nogueira PR, Weiblen R, Flores EF. Vaccinia viruses isolated from skin infection in horses produced cutaneous and systemic disease in experimentally infected rabbits. Res Vet Sci. 2012;93(2):1070-1075.

7. Flores EF, Weiblen R, Botton SA, Medeiros M, Irigoyen LF, Driemeier D, Schuch LF, Moraes MS. A retrospective search for bovine respiratory syncytial virus (BRSV) antigens in histological specimens by immunofluorescence and immunohistochemistry. Pesq Vet Bras. 2000; 20(4): 139-143.

8. Antoniassi NA, Pavarini SP, Henzel A, Flores EF, Driemeier D. Aspiration pneumonia associated with oesophageal myonecrosis in sheep due to BTV infection in Brazil. Vet Rec. 2010; 166(2):52-55.

9. Lucena RB, Pierezan F, Kommers GD, Irigoyen LF, Fighera RA, Barros CSL. Doenças de bovinos no Sul do Brasil: 6.706 casos. Pesq Vet Bras. 2010; 30(5): 428-434.

10. Roehe PM, Silva TC, Nardi NB, Oliveira LG, Rosa JCA. Diferenciação entre os vírus da rinotraqueíte infecciosa bovina (BHV-1) e herpesvírus da encefalite bovina (BHV-5) com anticorpos monoclonais. Pesq Vet Bras. 1997; 17(1): 41-44.

11. Elahi SM, Harpin S, Cornaglia E, Talbot B, Elazhary Y. Antigenic variation among bovine viral diarrhea virus (BVDV) strains and the role of different cell fixation methods in immunoassays. Can J Vet Res. 1997; 61(1):34-38 